\title{
Evolution of an Experimental Population of Phytophthora capsici in the Field
}

\author{
Amara R. Dunn, Stephen R. Bruening, Niklaus J. Grünwald, and Christine D. Smart
}

First, second, and fourth authors: Department of Plant Pathology and Plant-Microbe Biology, Cornell University, Geneva, NY; second author: Hobart and William Smith Colleges, Geneva, NY; and third author: Horticultural Crops Research Laboratory, United States Department of Agriculture-Agricultural Research Service, Corvallis, OR.

Accepted for publication 27 March 2014.

\begin{abstract}
Dunn, A. R., Bruening, S. R., Grünwald, N. J., and Smart, C. D. 2014. Evolution of an experimental population of Phytophthora capsici in the field. Phytopathology 104:1107-1117.

Populations of the vegetable pathogen Phytophthora capsici are often highly diverse, with limited gene flow between fields. To investigate the structure of a newly established, experimental population, an uninfested research field was inoculated with two single-zoospore isolates of $P$. capsici in September 2008. From 2009 through 2012, $\approx 50$ isolates of $P$. capsici were collected from the field each year and genotyped using five

High levels of diversity were detected in the research field, with 26 to 37 unique multilocus genotypes detected each year. Through 2012, genotypic diversity did not decline and no evidence of genetic drift was observed. However, during the 2011 and 2012 growing seasons, four new alleles not present in either parental isolate were observed in the field. Selfing (but not apomixis) was observed at low frequency among in vitro progeny. In addition, evidence for loss of heterozygosity was observed in half of the in vitro progeny. These results suggest that recombination, mutation, and loss of heterozygosity can affect the genetic structure observed in $P$. capsici populations.
\end{abstract} microsatellite loci. The same two isolates were also crossed in the lab.

Phytophthora capsici causes Phytophthora blight on many vegetables, including cucurbits, pepper, tomato, eggplant, snap bean, and lima bean (20). The asexual spores of $P$. capsici (sporangia and zoospores) are relatively short lived in the absence of susceptible plant tissue, and cannot survive in soil from one growing season to another in temperate climates (5). In contrast, the sexual spores (oospores) have thick walls and can remain viable in field soil for at least 3 years $(3,33)$. Because $P$. capsici is heterothallic, both mating types (designated A1 and A2) must be present for oogonia and antheridia (gametangia required for oospore formation) to be produced. Uchida and Aragaki (48) interpreted the formation of oospores from antheridia and oogonia in a paired culture of two $P$. capsici isolates of opposite mating type separated by a membrane as evidence for selfing. However, they did not attempt to determine the viability of these oospores and confirm that they were the results of selfing. Shattock et al. (45) grew several A1 isolates of $P$. infestans with an A2 isolate of either $P$. infestans or $P$. drechsleri, separated by a membrane, and genotyped some single-oospore progeny at two enzyme loci, concluding that at least some progeny were the products of selfing. Several studies have found no evidence of selfing in crosses of $P$. capsici $(12,26,34)$. Throughout this article, we will use the term "selfing" to describe the formation of a diploid oospore from an antheridium and an oogonium produced by the same individual, following meiosis, while "apomixes" will be used to describe the formation of an oospore through mitosis, without meiosis. Thus, selfing could involve recombination within an individual, resulting in progeny that differ from the parent,

\section{Corresponding author: C. D. Smart; E-mail address: cds14@ cornell.edu}

* The $\boldsymbol{e}$-Xtra logo stands for "electronic extra" and indicates that the online version contains six supplementary figures.

http://dx.doi.org/10.1094/PHYTO-12-13-0346-R

(c) 2014 The American Phytopathological Society whereas apomixis would result in progeny genetically identical to the parent.

Phytophthora blight epidemics in temperate climates are initiated by the germination of oospores and can be sustained by mixed sexual (oospores) and asexual (sporangia and zoospores) reproduction. Although studies have shown that the percentage of viable $P$. capsici oospores recovered from field soil declines over time $(3,5)$, it is unknown what proportion of oospores germinate within a year of formation. In a field that has been infested with $P$. capsici for some time, and where susceptible crops have been present for multiple years, the oospores that germinate in any given season might have been formed two or more years earlier. In addition, although Satour and Butler reported that oospore germination improved after a resting period of at least 1 month (43), to the best of our knowledge, no published studies have investigated how many sexual cycles of $P$. capsici can take place during a growing season. If oospores can mature and germinate within a month of formation then, theoretically, progeny from oospores formed early in the season could produce more oospores by the end of the growing season, resulting in more than one generation of the pathogen per season.

Based on studies conducted in Peru (25) and Argentina (18), populations of $P$. capsici can be predominantly clonal. A study of isolates collected from pepper in the Gansu province of China found evidence for three distinct clonal lineages (with genetic diversity within each lineage), in spite of the fact that both mating types were recovered from single fields (23). Surveys of $P$. capsici in the United States have also reported the frequent presence of both mating types in a single field but also high levels of diversity, low gene flow between fields, and no evidence that clonal lineages persist over time $(13,33)$. The fact that recombination occurs, particularly when oospores serve as a means of surviving the winter, might explain the high levels of diversity observed in U.S. populations, in spite of limited gene flow between fields. In addition, $P$. capsici has been described as a very "plastic" organism, capable of changing and adapting rapidly, and studies 
investigating the potential for development of fungicide resistance in $P$. capsici are consistent with this observation $(4,36)$.

There are several likely mechanisms by which $P$. capsici could first be introduced into a new field. $P$. capsici has frequently been isolated from surface water used for irrigation $(17,27,42,51)$; therefore, irrigating with infested water could certainly move the pathogen between fields. In New York, new outbreaks of Phytophthora blight in previously unaffected fields have occurred following major flooding events, and the introduction of $P$. capsici has also been traced to the movement of tractors or trucks between infested and uninfested fields, presumably carrying spores in soil on tires (C. D. Smart, unpublished). A single infected fruit may contain numerous oospores of both A1 and A2 mating type (32); therefore, the dumping of a few infected fruit in a previously uninfested field could also establish a permanent, sexually reproducing population. In one instance, $P$. capsici was brought onto a farm in earthworm castings used as fertilizer (35).

The establishment of a sexual population of $P$. capsici in a new field requires the introduction of at least two genetically distinct isolates where one is of each mating type; however, the genotypic diversity resulting from a founding population depends on the allelic diversity introduced. Based on the high levels of differentiation reported between populations in even nearby fields $(13,33)$, gene flow between fields is likely to be low, once a new population is established. This study was undertaken to establish a sexually reproducing experimental population of $P$. capsici by introduction of two parental genotypes characterized by microsatellite markers, and to monitor evolution of this population over subsequent years. Such a scenario is similar to what could occur in a commercial vegetable field when $P$. capsici is first introduced and the grower successfully prevents subsequent reintroductions. The objectives of this study were to determine whether, during the first 4 years following the founding of the population, (i) a sexual population would establish after introduction of strains of opposite mating type, (ii) genetic drift would occur given the relatively small population size found in a single field, and (iii) new alleles would be identified in the population.

\section{MATERIALS AND METHODS}

Field inoculation. Pumpkin (Cucurbita maxima and $C$. moschata 'Capital', 'Superior', 'Summit', 'Olga', 'Magician', 'Magic Wand', 'Merlin', 'Magic Lantern', 'Warlock', 'Super Herc', 'Aladdin', 'Gladiator', 'Bumpkin', 'Munchkin', 'Iron Man', 'Cannon Ball', and 'Snack Jack') were direct seeded on 25 June 2008 into a 0.8-ha field at the New York State Agricultural Experiment Station in Geneva, NY. In total, $\approx 200$ seeds were sown in rows on $\approx 0.05$ ha of the field, with $1.8 \mathrm{~m}$ between rows and $1.2 \mathrm{~m}$ between plants in a row. The field had no history of $P$. capsici infestation and was located on a research farm with no history of $P$. capsici, where only nonhosts (shrub willow, tree fruit, grape, and other small fruit) are grown. None of the other research farms at the New York State Agricultural Experiment Station have a history of $P$. capsici. Pumpkin plants (all highly susceptible to $P$. capsici) remained free of $P$. capsici symptoms through July and August 2008, until after they were inoculated on 8 September 2008, although there was adequate rainfall (8.76, 12.67, and $10.57 \mathrm{~cm}$ in June, July, and August, respectively) during the season. The single-zoospore isolates used for inocu- lation were NY 0664-1 (A1 mating type, isolated from sweet pepper) and NY 06180-4 (A2 mating type, isolated from butternut squash). Both were collected in 2006 from farms in central New York, are sensitive to the fungicide mefenoxam, and were previously characterized (13) using published microsatellite markers $(37,51)$ (Table 1). To produce inoculum for the field, each isolate was grown separately for 6 to 12 weeks on a sterile mixture of V8 juice and vermiculite, as described previously (8). Equal volumes of vermiculite colonized with each isolate were mixed and spread throughout the pumpkin field (especially around the ripening fruit) at an approximate rate of 1 liter per $7.3 \mathrm{~m}$ of row. Decaying plant debris was left undisturbed in the field throughout the winter.

Collection of $\boldsymbol{P}$. capsici isolates from the field and characterization with microsatellite markers. Beginning with the 2009 field season, the $P$. capsici population in the research field described above was sampled annually by collecting isolates from symptomatic plants in the field. In the spring of 2009 , the entire 0.8 -ha field was tilled, and raised beds covered with plastic mulch were prepared in a section $(\approx 0.02 \mathrm{ha})$ of the area of the field where the pumpkin had been inoculated with $P$. capsici the previous fall. On 16 June $2009, \approx 150$ summer squash (3- to 4week-old 'Zucchini Elite') were transplanted into these beds, and plants with symptoms of Phytophthora blight (e.g., wilting and shriveled crown lesions) were collected over the next month. $P$. capsici was isolated from symptomatic plants and single-zoospore isolates were obtained and stored in sterile distilled water for further characterization, including mating type determination, as previously described (13). DNA extraction was performed as previously described (13) or by using a modified hexadecyltrimethylammonium bromide method (31), in which polyvinylpyrrolidone was excluded from extract buffer A. Isolates were confirmed as $P$. capsici by species-specific polymerase chain reaction (PCR), as previously described (13), and microsatellite genotypes were determined as described below. Similar protocols were followed to collect isolates of $P$. capsici from the same field in the summers of 2010 through 2012, with additional susceptible vegetables being planted in the field in subsequent years, either on black plastic or on bare ground (Table 2). In 2010 and 2011, the entire 0.8 -ha field was planted with various susceptible vegetables, including 'Mystic Plus' pumpkin, 'Celebrity' tomato, 'Zucchini Elite' summer squash, 'Red Knight' and 'Revolution' pepper, and 'Nadia' eggplant. In 2010, various cucumber cultivars ('Platinum', 'Diva', 'Green Finger', 'Silver Slicer', 'Picolino', 'Dasher II', and three unnamed breeding lines) were planted and, in 2011, 'Diva' and 'Little Leaf' cucumber were planted. In 2012, $\approx 0.13$ ha was planted with susceptible vegetables ('Celebrity' tomato; 'Zucchini Elite' summer squash; 'Intruder', 'Paladin', 'Red Knight', and 'Revolution' pepper; and 'Nadia' eggplant). No subsequent inoculations of $P$. capsic $i$ were made in the field. In all years, pumpkin were grown on bare ground and other vegetables were grown on raised beds covered with plastic mulch. In crops grown on raised beds, natural rainfall was supplemented as needed by irrigation via drip tape laid under the plastic.

In vitro cross between parental isolates. The same singlezoospore isolates used in the field (NY 0664-1 and NY 06180-4) were crossed in the lab, and single germinating oospore isolates were obtained using protocols modified from Donahoo and Lamour (12). Agar containing mature oospores was homogenized

TABLE 1. Multilocus genotypes of two single zoospore isolates of Phytophthora capsici used to inoculate a research field and crossed in the laboratory

\begin{tabular}{|c|c|c|c|c|c|c|c|c|c|c|c|}
\hline \multirow{3}{*}{$\frac{\text { Isolate }}{\text { NY 0664-1 }}$} & \multirow{3}{*}{$\frac{\mathrm{MT}}{\mathrm{A} 1}$} & \multicolumn{10}{|c|}{ Allele sizes (bp) } \\
\hline & & \multicolumn{2}{|c|}{ Pcap1 } & \multicolumn{2}{|c|}{ Pcap3 } & \multicolumn{2}{|c|}{ Pcap5 } & \multicolumn{2}{|c|}{ Pcap7 } & \multicolumn{2}{|c|}{ SSRPC26 } \\
\hline & & 241 & 241 & 434 & 446 & 277 & 277 & 377 & 386 & 186 & 186 \\
\hline NY 06180-4 & $\mathrm{A} 2$ & 241 & 241 & 434 & 446 & 274 & 291 & 359 & 359 & 186 & 189 \\
\hline
\end{tabular}

a Mating type (MT) of each isolate and alleles (designated by length in base pairs) present at each of five microsatellite loci are shown. 
in a round-bottom 2-ml microcentrifuge tube with a $4.5-\mathrm{mm}$ sterile zinc-plated steel BB (Daisy Outdoor Products, Rogers, AR) and sterile distilled water by shaking in a TissueLyser (Qiagen, Valencia, CA) at $30 \mathrm{~Hz}$ for $30 \mathrm{~s}$, twice. Several layers of cheesecloth were then used to filter out agar chunks and mycelial debris. Following the treatment with Trichoderma harzianum lysing enzyme (Sigma Aldrich, St. Louis), the oospores were also treated with $0.1 \% \mathrm{KMnO}_{4}$ (Sigma Aldrich), as described by Pavon et al. (38), then incubated in sterile water at $4^{\circ} \mathrm{C}$ for 3 days, then at room temperature for 3 to 4 days, before being spread on water agar plates. Single germinating oospores were picked within $24 \mathrm{~h}$ with the aid of a dissecting microscope and transferred to PARP media (44), with 0.025 rather than $0.1 \mathrm{~g}$ of pentachloronitrobenzene. For each single-oospore isolate, mating type was determined, DNA was extracted from mycelia, isolates were confirmed as $P$. capsici by species-specific PCR, and alleles present at five microsatellite loci were determined as with isolates from the research field.

On-farm population. A naturally occurring reference population from a farm near Albany, NY was previously sampled for $P$. capsici in 2007 (13) and was utilized for comparison with the experimental population. In total, 23 single-zoospore isolates were collected from this farm in a single pumpkin field (planted with multiple cultivars) and characterized for microsatellite genotype as described below. This field had the highest level of diversity observed among fields sampled in New York (13). To the best of our knowledge, it had been fallow for at least several years prior to 2007, although it is adjacent to a river and downstream of other fields infested with $P$. capsici. Therefore, it has likely experienced multiple introductions of $P$. capsici via flooding. Alleles from locus SSRPC26 were also amplified from DNA previously extracted from these isolates (as described below). Isolates from this farm are hereafter referred to as sample CD-4.

Simple sequence repeat analysis. For all isolates, alleles present at microsatellite loci Pcap1, Pcap3, Pcap5, and Pcap7 were determined as previously described (13). These loci are not in coding regions of the genome, nor are they under selective pressure (37). In addition, alleles present at another microsatellite locus (SSRPC26) were determined using primers and amplification conditions described by Wang et al. (51), with the modification that the $5^{\prime}$ end of the forward primer was labeled with 6FAM (Applied Biosystems, Carlsbad, CA). Primers for this locus were designed from a database of expressed sequence tags (51). Based on the published genetic map of $P$. capsici (34) and a search of the $P$. capsici genome (http://genome.jgi.doe.gov/ Phyca11/Phyca11.home.html), loci Pcap3 and Pcap5 appear to be located on linkage groups 14 and 1, respectively. The locations of loci Pcap1, Pcap7, and SSRPC26 cannot be determined based on the current assembly of the genome.

Presence of novel alleles not expected given parental strains was confirmed by sequencing. If the isolate was homozygous at the locus in question, the PCR amplicon of the locus was directly sequenced on a 3730XL (Sanger) DNA Analyzer (Applied
Biosystems) at the Cornell University Life Sciences Core Laboratories Center. If the isolate was heterozygous at the locus, the PCR amplicons were cloned using a TOPO TA cloning kit (Invitrogen Life Technologies, Grand Island, NY) and sequenced as described above. In total, $\approx 10$ clones were sequenced per isolate.

Statistical analysis. For the purpose of analysis, isolates collected in a single season from the research field (or all isolates from the in vitro cross) were considered to be a population sample, for a total of six samples (isolates from the in vitro cross, isolates collected from the field in 2009 through 2012, and isolates from the naturally infested field CD-4). Unless otherwise noted, all analyses were conducted on both clone-corrected and total data (22). When calculating the number of unique multilocus genotypes (MLGs) and clone-correcting data, mating type was treated as a sixth locus but mating-type data was not used in the calculation of other parameters (either prior to or following clone correction.)

Population differentiation was determined in Arlequin version 3.5 (15), without assuming a stepwise mutation model, because preliminary analysis indicated that mutations in the research field population did not involve the addition or subtraction of a single copy of the repeat motif. In order to test for significant differentiation between samples or between host plants from which field isolates were obtained (pumpkin, summer squash, and tomato only), pairwise $\mathrm{F}_{\mathrm{ST}}$ values were calculated and their significance tested using 1,000 permutations. These three hosts were chosen because similar and comparatively large (42 to 63) numbers of isolates were collected from each of these hosts over the four growing seasons. The fixation index $\left(\mathrm{F}_{\mathrm{IS}}\right)$ was calculated for each of the six samples, and significance of these values was tested using 5,040 permutations. If calculated $\mathrm{F}_{\mathrm{IS}}$ values were negative, then $P$ values were subtracted from 1 because Arlequin performs a one-sided test (i.e., is $\mathrm{F}_{\mathrm{IS}}$ significantly $>0$ ). Both $\mathrm{F}_{\mathrm{ST}}$ values and $F_{I S}$ were calculated based on differences in allele frequencies (not allele sizes). Whether each polymorphic locus was in Hardy-Weinberg equilibrium was tested using a Markov chain with 1,000,000 steps and 100,000 dememorization steps, on clone corrected data only.

The "poppr" package (30) in R version 3.0.1 (41) was used to identify the number of MLGs in each sample (based on alleles and mating type of each isolate), and to generate a clone-corrected data set. Clone correction was performed within each of the six samples (not across all samples). This program was also used to calculate the following values for each sample: Stoddart and Taylor's index of MLG diversity (47), the index of association $\left(I_{A}\right)(6)$, evenness $\left(E_{5}\right)(21)$, and the expected number of MLGs (eMLGs) at the smallest common sample size, using rarefaction (24). Significance was tested with 999 permutations. The poppr package was also used to draw dendrograms for all isolates together and for each of the six population samples based on Bruvo's genetic distance (7) using the unweighted pair-group method with arithmetic averages with 999 permutations and a bootstrap value cutoff of $70 \%$. Minimum spanning networks were

TABLE 2. Phytophthora capsici populations sampled from either a controlled laboratory cross or sampled over time from infected host plants after inoculation of a research field with parental isolates NY 0664-1 and NY 06180-4 in $2008^{\mathrm{a}}$

\begin{tabular}{|c|c|c|c|c|c|}
\hline \multirow[b]{2}{*}{ Host plant } & \multicolumn{5}{|c|}{ Number of isolates } \\
\hline & In vitro cross & Field 2009 & Field 2010 & Field 2011 & Field 2012 \\
\hline Pumpkin & - & - & 32 & 10 & - \\
\hline Tomato & - & - & 23 & 18 & 18 \\
\hline Cucumber & - & - & 0 & 7 & - \\
\hline Pepper & - & - & 0 & 18 & 18 \\
\hline Eggplant & - & - & 0 & 4 & 0 \\
\hline
\end{tabular}

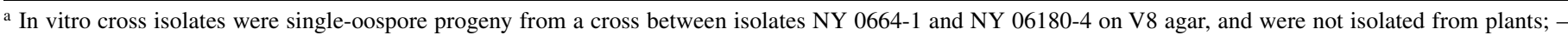
indicates that this host was not planted in the field in this season. 
also drawn based on Bruvo's genetic distance. Both minimum spanning networks and dendrograms were drawn only using clone corrected data.

To test whether the ratio of isolates with A1 mating type to isolates with A2 mating type differed significantly from the expected 1:1 ratio, a $\chi^{2}$ goodness-of-fit test was performed (46). GenAlEx version $6.5(39,40)$ was used to calculate allele frequencies following clone correction.

\section{RESULTS}

Isolate collection from the field and amplification of alleles at microsatellite loci. Within 2 weeks of inoculation, pumpkin vines began to wilt and, by 9 October 2008, most vines were dead and many fruit had developed lesions typical of infection by $P$. capsici. Beginning in 2009, between 46 and 60 single-zoospore isolates of $P$. capsici were collected from the inoculated research field each year from various hosts (Table 2). In eggplant, $P$. capsici was only isolated from symptomatic fruit on plants that appeared otherwise healthy, whereas $P$. capsici was isolated from crown, stem, and fruit tissue of other hosts.

Genotypic diversity observed in research field population. $P$. capsici established itself well in our experimental field as a population characterized by high genotypic diversity, high turnover of genotypes, mixed reproduction, sexuality (after clone correction), and Hardy-Weinberg equilibrium. Between 26 and 37 unique MLGs were identified among isolates collected from the field per year (Table 3). In each year, multiple isolates were collected from the research field with identical MLGs but the most frequently detected MLG was not identical across years. In addition, the number of MLGs detected in multiple isolates varied among years. In 2009, more than half of the MLGs were identified in at least two isolates whereas, in 2012, one MLG was predominant, with most of the remaining MLGs detected in only one isolate (Fig. 1). In all, of 81 unique MLGs identified in the four research field samples, 52 were only detected in 1 year; 19 and 10 unique MLGs were detected in 2 or 3 years, respectively; and no MLG was detected in all 4 years. No isolates collected from the research field were identical to either parental isolate. Prior to clone correction, values for Stoddart and Taylor's index $(G)$ were similar, except for the field sample from 2012, which had much lower genotypic diversity. A similar trend was seen in the expected number of MLGs calculated for each sample using rarefaction (Table 3 ). Prior to clone correction, $E_{5}$ was fairly close to 1 in field samples from 2009 through 2011 but $<0.5$ in 2012. In sample CD-4, 22 unique MLGs were identified among 23 isolates, and no MLGs were detected in both CD-4 and the research field. The value of $G$ for sample CD-4 was similar to values observed in the research field samples from 2009 through 2011, prior to clone correction, but the number of expected MLGs was higher. Evenness in field CD-4 was nearly 1 prior to clone correction (Table 3).

Mating type ratios and the $I_{A}$ indicate that the research field population was sexual after clone correction. The mating type ratio in most years (with the exception of 2011) did not deviate significantly from the expected 1:1 ratio, and the $\mathrm{F}_{\mathrm{IS}}$ was not significantly different from zero $(P=0.05)$ (Table 4$)$. The observed $I_{A}$ was not significantly different from randomly permuted samples, indicating that the population is sexual (Table 4). Following clone correction, approximately half of the polymorphic loci were in Hardy-Weinberg equilibrium, except in the 2012 field sample, when four of five loci were in Hardy-Weinberg equilibrium.

Differentiation and divergence in the research field population. Pairwise $\mathrm{F}_{\mathrm{ST}}$ values comparing field isolates from 2009 through 2012 ranged from -0.012 to 0.001 following clone correction, and none were significantly different from zero at $P=$ 0.05 (data not shown). Pairwise $\mathrm{F}_{\mathrm{ST}}$ values comparing sample CD-4 to all other samples were significantly different from zero $(P<0.01)$, with $\mathrm{F}_{\mathrm{ST}}$ values of 0.156 to 0.216 , following clone correction. Among pairwise $\mathrm{F}_{\mathrm{ST}}$ values comparing isolates collected from different hosts in 2009 through 2012 (pumpkin, summer squash, and tomato only), no values were significantly different from zero at $P=0.05$, following clone correction.

The dendrogram of all isolates showed little structure (data not shown), with only two bootstrap values exceeding the $70 \%$ cutoff. Many isolates from the CD-4 sample tended to cluster together but not in a single clade. Isolates from the four field samples did not cluster together by year, nor did progeny from the in vitro cross. Similarly, when dendrograms were drawn for each sample individually, few bootstrap values exceeded the $70 \%$ cutoff, and they showed few changes between years in samples from the

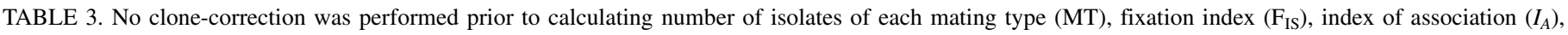
evenness $\left(E_{5}\right)$, and number of unique multilocus genotypes (MLGs) detected among Phytophthora capsici isolates from each of six populations ${ }^{\mathrm{a}}$

\begin{tabular}{|c|c|c|c|c|c|c|}
\hline \multirow[b]{2}{*}{ Variables } & \multicolumn{6}{|c|}{ Sample } \\
\hline & In vitro cross & Field 2009 & Field 2010 & Field 2011 & Field 2012 & CD-4 \\
\hline \multicolumn{7}{|l|}{ MT } \\
\hline A1 & 25 & 17 & 22 & 21 & 16 & 9 \\
\hline $\mathrm{A} 2$ & 28 & 30 & 38 & 37 & 30 & 14 \\
\hline$\chi^{2} P$ value ${ }^{\mathrm{b}}$ & NS & NS & 0.039 & 0.036 & 0.039 & NS \\
\hline $\mathrm{F}_{\mathrm{IS}} \mathrm{c}$ & -0.102 & -0.127 & -0.041 & -0.031 & 0.219 & 0.265 \\
\hline$P$ value & 0.042 & 0.020 & NS & NS & $<0.001$ & $<0.001$ \\
\hline$I_{A}^{\mathrm{d}}$ & 0.065 & -0.002 & 0.141 & 0.106 & 0.803 & 0.096 \\
\hline$P$ value & 0.047 & NS & 0.001 & 0.007 & 0.001 & NS \\
\hline$G^{\mathrm{e}}$ & 22.12 & 21.45 & 18.75 & 24.03 & 6.49 & 21.16 \\
\hline$E_{5}{ }^{\mathrm{f}}$ & 0.84 & 0.88 & 0.76 & 0.81 & 0.41 & 0.98 \\
\hline eMLG & 18 & 18 & 17 & 18 & 15 & 22 \\
\hline Unique MLGs ${ }^{\mathrm{h}}$ & 31 & 27 & 30 & 37 & 26 & 22 \\
\hline Total isolates & 53 & 47 & 60 & 58 & 46 & 23 \\
\hline
\end{tabular}

a Sample CD-4 includes isolates collected from a commercial farm in New York in 2007, which has been previously described and is included for comparison.

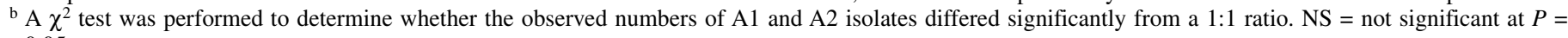
0.05 .

c Whether $\mathrm{F}_{\mathrm{IS}}$ values are significantly different from zero was tested in Arlequin version $3.5(15)$ with 5,040 permutations. NS $=$ not significant at $P=0.05$.

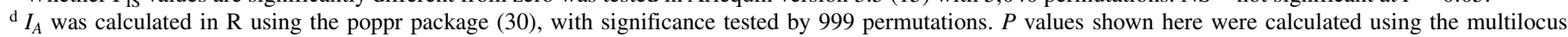
permutation method (2). NS = not significant at $P=0.05$.

e Stoddart and Taylor's index $(G)$ of MLG diversity was calculated in R using the poppr package (30).

${ }^{\mathrm{f}}$ Calculated in $\mathrm{R}$ using the poppr package (30).

$\mathrm{g}$ Number of expected MLGs based on rarefaction if each sample contained 23 individuals was calculated in $\mathrm{R}$ using the poppr package (30).

h Number of unique MLGs identified in each population using mating type and alleles present at five microsatellite loci. 
research field (Supplementary Figures 1 to 6). In the minimum spanning network, MLGs from sample CD-4 generally clustered together, although not on a single branch of the network (Fig. 2). Similar to the dendrogram, MLGs from the in vitro progeny or each of the research field samples generally did not cluster together.

Allele frequencies in field samples. Based on the fact that all alleles present in the parental isolates were observed each year in the research field, little genetic drift was observed in the first four years since the establishment of this population. At loci Pcap1, Pcap3, Pacp5, and SSRPC26, allele frequencies in the 2009 field sample did not differ markedly from those expected in the F1 generation based on the genotypes of the parent isolates (Table 5). However, at locus Pcap7, the frequency of the 359-bp allele was substantially less than expected, and the frequencies of the 377-bp
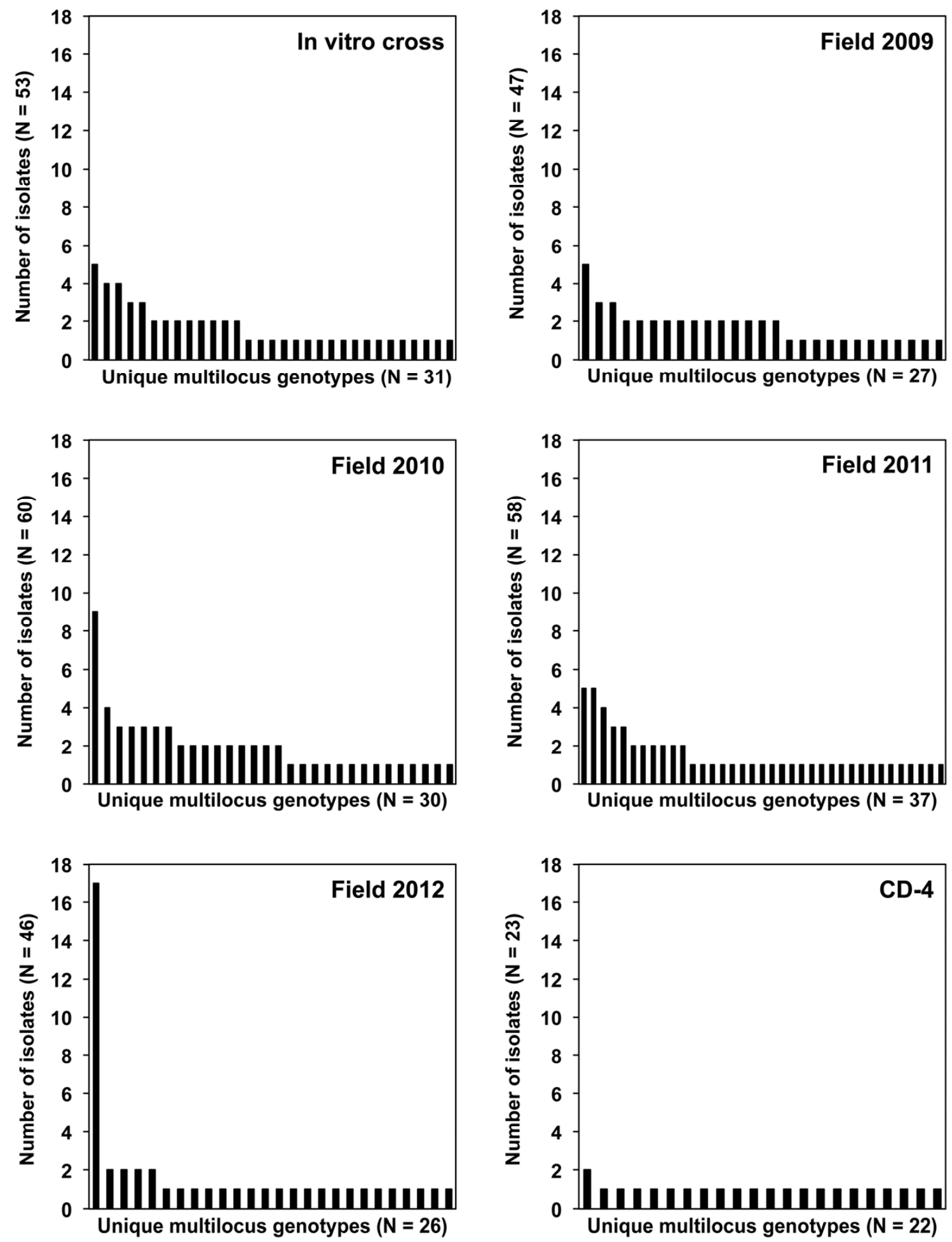

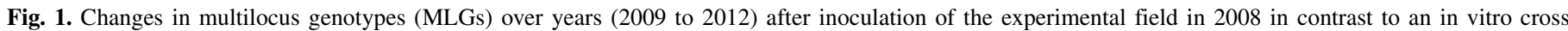

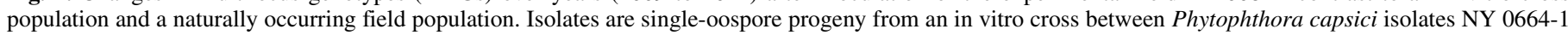

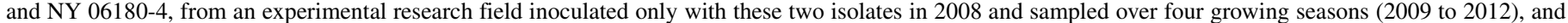

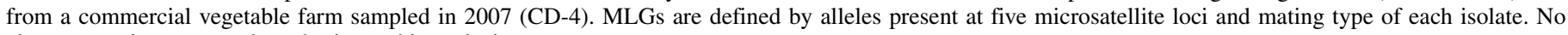
clone correction was conducted prior to this analysis. 
allele (and, to a lesser extent, the 386-bp allele) were greater than expected in the 2009 field sample compared with expected allele frequencies in an F1 generation from this cross. Between 2009 and 2011, allele frequencies at all loci remained relatively constant, with the exception that, in 2012, the frequency of the 274-bp allele at locus Pcap5 decreased while the frequency of the 291-bp allele increased (Table 5).

Detection of rare, novel alleles at loci Pcap1 and Pcap7. At locus Pcap1, the parental isolates used to inoculate the field were both homozygous for a 241-bp allele. However, two alleles (233 and $260 \mathrm{bp}$ ) that were not present in either parental isolate or in field isolates from previous years were identified in the 2011 field sample. Each new allele was observed in one isolate that was heterozygous at this locus with the 241-bp allele from the parental isolates. Based on sequencing, the 233-bp allele had an 8-bp deletion outside of the repeat region of the locus, compared with the 241-bp allele present in NY 0664-1 and NY 06180-4. The 260-bp allele had three additional copies of the AC repeat motif in

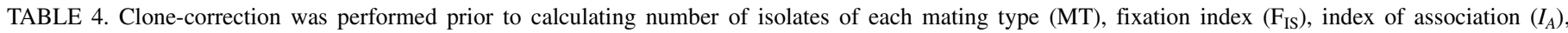
evenness $\left(E_{5}\right)$, and the number of unique multilocus genotypes (MLGs) detected among Phytophthora capsici isolates from each of six populations ${ }^{\mathrm{a}}$

\begin{tabular}{|c|c|c|c|c|c|c|}
\hline \multirow[b]{2}{*}{ Variables } & \multicolumn{6}{|c|}{ Sample } \\
\hline & In vitro cross & Field 2009 & Field 2010 & Field 2011 & Field 2012 & CD-4 \\
\hline \multicolumn{7}{|l|}{ MT } \\
\hline A1 & 17 & 11 & 16 & 11 & 14 & 9 \\
\hline $\mathrm{A} 2$ & 14 & 16 & 14 & 26 & 12 & 13 \\
\hline$\chi^{2} P$ value $^{\mathrm{b}}$ & NS & NS & NS & 0.014 & NS & NS \\
\hline $\mathrm{F}_{I S} \mathrm{c}$ & -0.058 & -0.094 & -0.104 & 0.015 & 0.135 & 0.275 \\
\hline$P$ value & NS & NS & NS & NS & NS & $<0.001$ \\
\hline$I_{A}{ }^{\mathrm{d}}$ & -0.052 & -0.094 & -0.072 & 0.006 & 0.061 & 0.068 \\
\hline$P$ value & NS & NS & NS & NS & NS & NS \\
\hline$G^{\mathrm{e}}$ & 29.12 & 27 & 30 & 33.39 & 26 & 22 \\
\hline$E_{5}{ }^{\mathrm{f}}$ & 0.98 & 1 & 1 & 0.97 & 1 & 1 \\
\hline $\mathrm{eMLG}^{\mathrm{g}}$ & 22 & 22 & 22 & 21 & 22 & 22 \\
\hline Total isolates & 31 & 27 & 30 & 37 & 26 & 22 \\
\hline
\end{tabular}

a Sample CD-4 includes isolates collected from a commercial farm in New York in 2007, which has been previously described and is included for comparison.

${ }^{\mathrm{b}} \mathrm{A} \chi^{2}$ test was performed to determine whether the observed numbers of A1 and A2 isolates differed significantly from a 1:1 ratio. NS $=$ not significant at $P=0.05$.

${ }^{c}$ Whether $\mathrm{F}_{\mathrm{IS}}$ values are significantly different from zero was tested in Arlequin version $3.5(15)$ with 5,040 permutations. NS $=$ not significant at $P=0.05$.

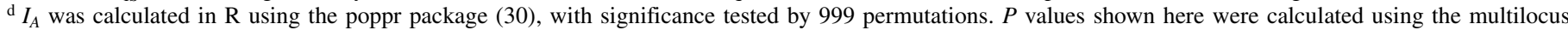
permutation method (2). NS $=$ not significant at $P=0.05$.

e Stoddart and Taylor's index $(G)$ of MLG diversity was calculated in R using the poppr package (30).

f Calculated in $\mathrm{R}$ using the poppr package (30).

g Number of expected MLGs based on rarefaction if each sample contained 22 individuals was calculated in $\mathrm{R}$ using the poppr package (30).

TABLE 5. Frequencies of alleles observed at five microsatellite loci in Phytophthora capsici isolates from six populations ${ }^{\mathrm{a}}$

\begin{tabular}{|c|c|c|c|c|c|c|c|}
\hline \multirow[b]{2}{*}{ Locus, size $(b p)^{b}$} & \multicolumn{7}{|c|}{ Allele frequencies } \\
\hline & Expected $^{c}$ & In vitro cross & 2009 & 2010 & 2011 & 2012 & CD-4 \\
\hline \multicolumn{8}{|l|}{ Pcap1 } \\
\hline 233 & 0 & 0 & 0 & 0 & 0.01 & 0.02 & 0.05 \\
\hline 239 & $\ldots$ & 0 & 0 & 0 & 0 & 0 & 0.11 \\
\hline 241 & 1.00 & 1.00 & 1.00 & 1.00 & 0.97 & 0.96 & 0.84 \\
\hline 260 & 0 & 0 & 0 & 0 & 0.01 & 0.02 & 0 \\
\hline \multicolumn{8}{|l|}{ Pcap3 } \\
\hline 434 & 0.50 & 0.45 & 0.50 & 0.55 & 0.58 & 0.52 & 0.70 \\
\hline 440 & $\ldots$ & 0 & 0 & 0 & 0 & 0 & 0.23 \\
\hline 446 & 0.50 & 0.55 & 0.50 & 0.45 & 0.42 & 0.48 & 0.07 \\
\hline \multicolumn{8}{|l|}{ Pcap5 } \\
\hline 274 & 0.25 & 0.18 & 0.31 & 0.23 & 0.24 & 0.10 & 0.70 \\
\hline 277 & 0.50 & 0.58 & 0.48 & 0.50 & 0.51 & 0.54 & 0 \\
\hline 291 & 0.25 & 0.24 & 0.20 & 0.27 & 0.24 & 0.37 & 0.23 \\
\hline 299 & $\ldots$ & 0 & 0 & 0 & 0 & 0 & 0.05 \\
\hline 302 & $\ldots$ & 0 & 0 & 0 & 0 & 0 & 0.02 \\
\hline \multicolumn{8}{|l|}{ Pcap7 } \\
\hline 359 & 0.50 & 0.23 & 0.28 & 0.25 & 0.19 & 0.29 & 0 \\
\hline 374 & $\ldots$ & 0 & 0 & 0 & 0 & 0 & 0.02 \\
\hline 377 & 0.25 & 0.27 & 0.41 & 0.38 & 0.42 & 0.40 & 0.39 \\
\hline 380 & $\ldots$ & 0 & 0 & 0 & 0 & 0 & 0.16 \\
\hline 383 & $\ldots$ & 0 & 0 & 0 & 0 & 0 & 0.27 \\
\hline 386 & 0.25 & 0.50 & 0.31 & 0.37 & 0.36 & 0.31 & 0.16 \\
\hline 389 & 0 & 0 & 0 & 0 & 0.01 & 0 & 0 \\
\hline 392 & 0 & 0 & 0 & 0 & 0.01 & 0 & 0 \\
\hline \multicolumn{8}{|l|}{ SSRPC26 } \\
\hline 183 & $\ldots$ & 0 & 0 & 0 & 0 & 0 & 0.11 \\
\hline 186 & 0.75 & 0.77 & 0.78 & 0.73 & 0.80 & 0.83 & 0.61 \\
\hline 189 & 0.25 & 0.23 & 0.22 & 0.27 & 0.20 & 0.17 & 0.27 \\
\hline
\end{tabular}

a Prior to calculating allele frequencies, isolates were clone corrected so that only one representative from each multilocus genotype (as defined by alleles at five microsatellite loci and mating type) was included. Sample CD-4 includes isolates collected from a commercial farm in New York in 2007, which has been previously described and is included for comparision.

b Size of each observed allele in base pairs.

${ }^{c}$ Expected allele frequencies based on alleles observed in parent isolates. 
addition to a string of 13 cytosine bases, amounting to a 19-bp addition in the repeat region of the locus compared with the parental allele. These alleles were also found in the 2012 field sample, observed in one isolate each as heterozygotes with the parental allele. The respective deletions and insertions occurred in the same positions in the locus as those observed in 2011. These alleles appear to be the result of insertions and do not follow the stepwise mutation model expected for microsatellites.

At locus Pcap7, two alleles (389 and 392 bp) were also identified in the 2011 field sample but were not present in either parental isolate. Each new allele was observed in one isolate that was heterozygous at this locus, and also contained an allele observed in one of the parental isolates. Sequencing of these new alleles confirmed that they contained one or two additional copies of the TTC repeat motif in the repeat region of the locus, compared with the largest allele observed in the two parental isolates (386 bp in isolate NY 0664-1). Neither of these new alleles was observed in isolates collected from the field in 2012. These alleles appear to have arisen by following a stepwise mutation model.

Oospore progeny from an in vitro cross behaves like the field population. Germinating oospores collected in vitro were the F1 progeny of a cross between $P$. capsici isolates NY 0664-1 and NY 06180-4. In total, 53 single-oospore isolates were col-

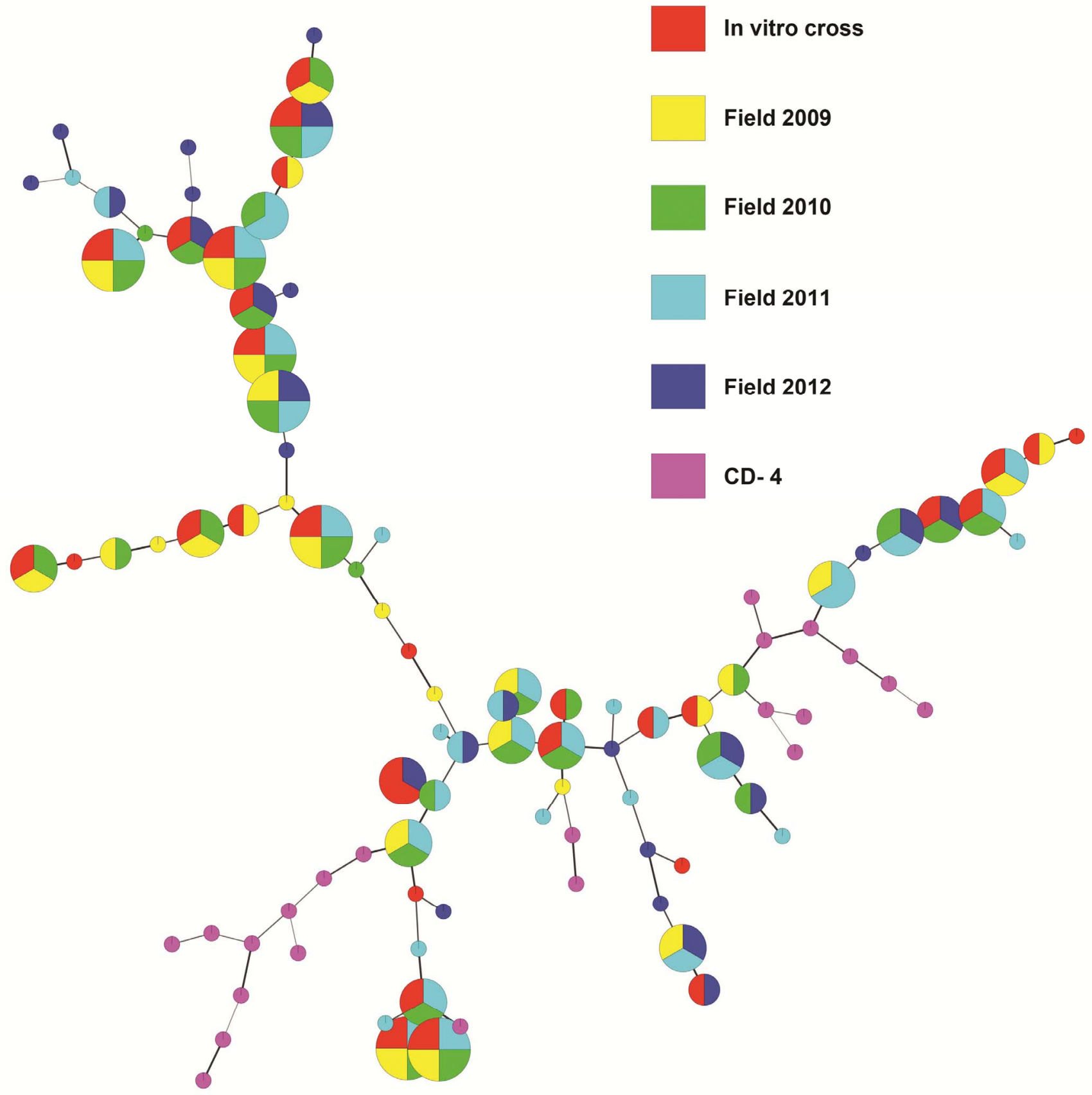

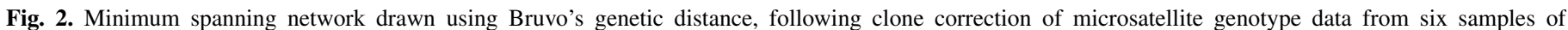

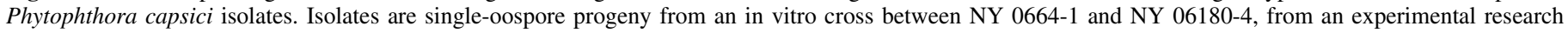

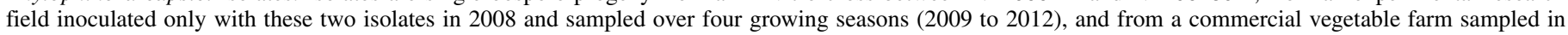

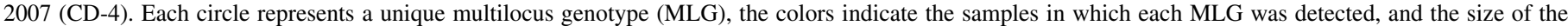

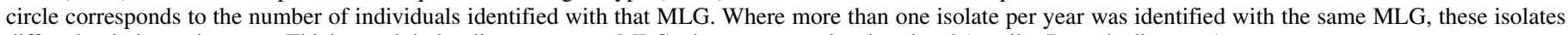
differed only in mating type. Thicker and darker lines represent MLGs that are more closely related (smaller Bruvo's distances). 
lected, and 22 of these were removed from analysis following clone correction. Among the 53 progeny, 31 unique MLGs were identified, with up to 5 progeny sharing an MLG (Fig. 1). Based on values for $G, E_{5}$, and eMLG, genotypic diversity of the in vitro progeny was similar to that observed in field samples, following clone correction (Table 4). Genotypic evenness was relatively close to one, even prior to clone correction (Table 3). Among the in vitro progeny, the ratio of $\mathrm{A} 1$ isolates to $\mathrm{A} 2$ isolates did not differ significantly from $1: 1$ at $P=0.05$ after clone correction, and the $F_{I S}$ was not significantly different from zero (Table 4). The $I_{A}$ was not significantly different from randomly permuted samples (Table 4). Similar to the research field population, half of the polymorphic loci were in Hardy-Weinberg equilibrium among the in vitro progeny following clone correction. No pairwise $F_{S T}$ values comparing clone-corrected progeny from the in vitro cross to research field samples from 2009 through 2012 were significantly different from 0 at $P=0.05$ (data not shown). However, pairwise $F_{S T}$ values were significantly different from zero when comparing the in vitro progeny to the CD-4 sample whether or not data were clone corrected.

All alleles present in the parent isolates were also observed among in vitro progeny and, at loci Pcap1, Pcap3, Pacp5, and SSRPC26, allele frequencies (following clone correction) did not differ markedly from expected frequencies based on the genotypes of the parent isolates. However, at locus Pcap7, the frequency of the 359-bp allele was substantially less than expected, and the frequency of the 386-bp allele was substantially greater than expected, as was seen in the 2009 research field sample (Table 5). No in vitro progeny were identical to either parent isolate, and no progeny shared the same MLG with isolates from sample CD-4.

Unusual patterns of inheritance. In the parent isolates NY 0664-1 and NY 06180-4, alleles at loci Pcap5 and Pcap7 were unique to either one parent or the other (Table 6). Thus, the A1 parent (NY 0664-1) could only contribute the 277-bp allele at locus Pcap5 and the 377- or 386-bp alleles at locus Pcap7 to oospore progeny in the F1 generation. Similarly, the A2 parent (NY 06180-4) could only contribute the 274- or 291-bp alleles at
Pcap5 and the 359-bp allele at locus Pcap7. Of the 53 singleoospore progeny from the in vitro cross, only 21 had an allele from each parent at both Pcap5 and Pcap7. The remaining 32 progeny appeared to inherit two alleles from one parent at one or both of these loci. In only a few of these progeny $(n=4)$ were alleles at both loci Pcap5 and Pcap7 from the same parent (always NY 0664-1), which could be consistent with selfing. No progeny had alleles only from parental isolate NY 06180-4. Many oospore progeny $(n=28)$ appeared to inherit alleles from both parents at locus Pcap5 but only an allele from NY 0664-1 at locus Pcap7 (either 377 or 386 bp) (Table 6). Over $>5$ years and 12 transfers in the lab, as well as inoculation and reisolation from hosts in the greenhouse, alleles at all five microsatellite loci have remained unchanged in isolates NY 0664-1 and NY 06180-4 (data not shown).

In the 2009 research field sample (the first time the field was sampled following inoculation but not necessarily the F1 generation), 20 of the isolates (representing 12 unique MLGs) collected from the field contained an allele from each parent at locus Pcap5 but only an allele from NY 0664-1 at locus Pcap7 (data not shown). These included some isolates collected early in the season on 22 June, only a week after the squash were transplanted into the field. One unique MLG (represented by two isolates collected on the same date) contained only the 274-bp allele at locus Pcap5 (from NY 06180-4) and only the 377-bp allele at locus Pcap7 (from NY 0664-1). No isolates collected from the field in 2009 contained only alleles from one parent or the other at both Pcap5 and Pcap7.

\section{DISCUSSION}

We successfully established a field population of $P$. capsici that reproduced both sexually and clonally but that appeared sexual (after clone correction), with mating types in the expected 1:1 ratio and no detectable linkage among microsatellite loci. In spite of the small number of loci being studied, substantial genotypic diversity was observed in this isolated research population of $P$. capsici. Furthermore, this diversity appears to be maintained over time (at least over 4 years following inoculation), and novel, rare

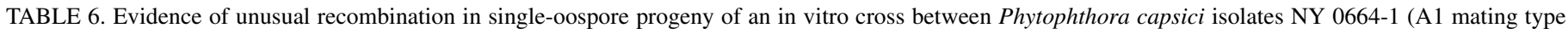
[MT]) and NY 06180-4 (A2 MT)

\begin{tabular}{|c|c|c|c|c|c|c|c|c|c|c|}
\hline \multirow[b]{3}{*}{ Type $^{a}$} & \multirow[b]{3}{*}{$N^{\mathrm{b}}$} & \multirow[b]{3}{*}{ MT } & \multicolumn{8}{|c|}{ Loci } \\
\hline & & & \multirow{2}{*}{$\begin{array}{l}\text { Pcap1 } \\
\text { Alleles }\end{array}$} & \multirow{2}{*}{$\begin{array}{l}\text { Pcap3 } \\
\text { Alleles }\end{array}$} & \multicolumn{2}{|c|}{ Pcap5 } & \multicolumn{2}{|c|}{ Pcap7 } & \multicolumn{2}{|c|}{ SSRPC26 } \\
\hline & & & & & Alleles & Parent $^{\mathrm{c}}$ & Alleles & Parent $^{\mathrm{c}}$ & Alleles & Parent $^{\mathrm{c}}$ \\
\hline NY 0664-1 & $\ldots$ & A1 & $241 / 241$ & $434 / 446$ & $277 / 277$ & $\ldots$ & $377 / 386$ & $\ldots$ & $186 / 186$ & $\ldots$ \\
\hline NY 06180-4 & $\ldots$ & $\mathrm{A} 2$ & $241 / 241$ & $434 / 446$ & $274 / 291$ & $\ldots$ & $359 / 359$ & $\ldots$ & $186 / 189$ & $\ldots$ \\
\hline Possible self & 1 & A1 & $241 / 241$ & $434 / 434$ & $277 / 277$ & NY 0664-1 & $386 / 386$ & NY 0664-1 & $186 / 186$ & Unknown \\
\hline Possible self & 1 & $\mathrm{~A} 2$ & $241 / 241$ & $434 / 434$ & $277 / 277$ & NY 0664-1 & $386 / 386$ & NY 0664-1 & $186 / 186$ & Unknown \\
\hline Possible self & 1 & A1 & $241 / 241$ & $446 / 446$ & $277 / 277$ & NY 0664-1 & $377 / 377$ & NY 0664-1 & $186 / 186$ & Unknown \\
\hline Possible self & 1 & A1 & $241 / 241$ & $446 / 446$ & $277 / 277$ & NY 0664-1 & $386 / 386$ & NY 0664-1 & $186 / 186$ & Unknown \\
\hline Other & 1 & $\mathrm{~A} 2$ & $241 / 241$ & $434 / 434$ & $277 / 277$ & NY 0664-1 & $386 / 386$ & NY 0664-1 & $186 / 189$ & Both \\
\hline Other & 3 & A1 & $241 / 241$ & $434 / 434$ & $277 / 291$ & Both & $386 / 386$ & NY 0664-1 & $186 / 189$ & Both \\
\hline Other & 5 & $\mathrm{~A} 2$ & $241 / 241$ & $434 / 446$ & $274 / 277$ & Both & $377 / 377$ & NY 0664-1 & $186 / 186$ & Unknown \\
\hline Other & 1 & A1 & $241 / 241$ & $434 / 446$ & $274 / 277$ & Both & $377 / 377$ & NY 0664-1 & $186 / 189$ & Both \\
\hline Other & 1 & A2 & $241 / 241$ & $434 / 446$ & $274 / 277$ & Both & $386 / 386$ & NY 0664-1 & $186 / 186$ & Unknown \\
\hline Other & 1 & A1 & $241 / 241$ & $434 / 446$ & $274 / 277$ & Both & $386 / 386$ & NY 0664-1 & $186 / 189$ & Both \\
\hline Other & 4 & A2 & $241 / 241$ & $434 / 446$ & $277 / 291$ & Both & $377 / 377$ & NY 0664-1 & $186 / 186$ & Unknown \\
\hline Other & 2 & A1 & $241 / 241$ & $434 / 446$ & $277 / 291$ & Both & $377 / 377$ & NY 0664-1 & $186 / 189$ & Both \\
\hline Other & 2 & $\mathrm{~A} 2$ & $241 / 241$ & $434 / 446$ & $277 / 291$ & Both & $386 / 386$ & NY 0664-1 & $186 / 186$ & Unknown \\
\hline Other & 3 & $\mathrm{~A} 1$ & $241 / 241$ & $434 / 446$ & $277 / 291$ & Both & $386 / 386$ & NY 0664-1 & $186 / 189$ & Both \\
\hline Other & 1 & A1 & $241 / 241$ & $446 / 446$ & $274 / 277$ & Both & $386 / 386$ & NY 0664-1 & $186 / 189$ & Both \\
\hline Other & 2 & A2 & $241 / 241$ & $446 / 446$ & $277 / 291$ & Both & $386 / 386$ & NY 0664-1 & $186 / 186$ & Unknown \\
\hline Other & 2 & A1 & $241 / 241$ & $446 / 446$ & $277 / 291$ & Both & $386 / 386$ & NY 0664-1 & $186 / 189$ & Both \\
\hline
\end{tabular}

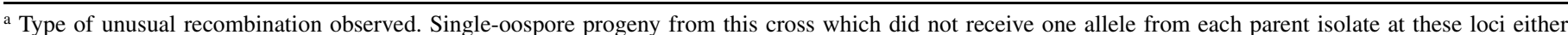
received only alleles from one parent (consistent with possible selfing) (Possible self), or received an allele from each parent at locus Pcap5 or SSRPC26 but only alleles from NY 0664-1 at locus Pcap7 (Other).

b Number of single-oospore progeny with the designated multilocus genotype.

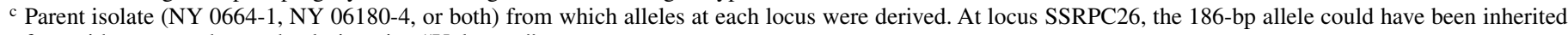
from either parent, hence the designation "Unknown". 
alleles were identified in the population during this time. It is likely that greater diversity, and possibly additional novel alleles, could be detected using additional loci or different genotyping methods. The fact that not all single-oospore progeny from the in vitro cross had unique MLGs is consistent with the hypothesis that this study underestimates diversity in the population. Therefore, detection of many MLGs in 2 or 3 years is not evidence for survival of asexual propagules of $P$. capsici over the winter in New York State. The fact that no isolates identical to either parent (even based on the small number of loci used in this study) were sampled from the field in 2009 is strong evidence that asexual propagules cannot survive the winter.

Previous studies have found evidence of apomixis but not selfing in crosses between $P$. capsici isolates or between $P$. capsici and the closely related $P$. tropicalis $(12,26)$. It seems likely that the potential for viable progeny to be produced via selfing or apomixis would vary among isolates, because Donahoo et al. (12) reported that proportions of apomictic compared with hybrid progeny varied between two separate crosses. Judelson (28) made similar observations of selfed versus hybrid progeny in $P$. infestans crosses. Although the presence of only alleles from isolate NY 0664-1 at two polymorphic loci in four progeny from the in vitro cross could be consistent with selfing, these genotypes could also have resulted from either a cross between the two parents or apomixis, followed (in either case) by loss of heterozygosity via gene conversion. Because both parental isolates had at least one allele in common at the other three loci studied, patterns of inheritance at these other loci are not informative in distinguishing among these possibilities. Alternative genotyping techniques would be needed to clarify which mechanism was responsible for the genotypes we observed. Similarly, with the microsatellite markers used in this study, it is not possible to determine whether selfing or apomixis occurred in the research field population. Although selfing may occur in the research field, it is likely less frequent than outcrossing, based on the lack of linkage observed among loci. This is in contrast to evidence of frequent selfing in field populations of the homothallic oomycete Aphanomyces euteiches (22).

Results presented here suggest that genotypic diversity remained high over four growing seasons in this isolated research population of $P$. capsici. Based on the high levels of diversity detected in on-farm populations of $P$. capsici in New York State, this was not surprising (13). The lower values of $G$ and the expected numbers of MLGs (prior to clone correction) in the 2012 research field sample are probably related to oversampling of a single dominant genotype, which spread asexually throughout the research field in 2012 as the season progressed, rather than to a decline in genotypic diversity by the fourth year after inoculation. Although values for $G$ were similar between the CD-4 population and the research field samples, the higher number of expected MLGs in the CD-4 population compared with the research field samples prior to clone correction suggests that diversity in this commercial field is higher than in the research field, as expected.

Because the overwintering spores of $P$. capsici are sexual (unless selfing is occurring), it is not surprising that the data presented here are consistent with a sexual population in this research field. Diversity in the founding population was low (two single-zoospore isolates); therefore, all progeny from these two parental isolates are relatively closely related, and mating among close relatives can result in higher $\mathrm{F}_{\text {IS }}$ values (19). However, this was not observed in this research population. Although the CD-4 population had a larger $F_{\text {IS }}$ compared with annual samples from the research field, the value is still consistent with random mating, and is similar to $F_{\text {IS }}$ values observed for other heterothallic oomycetes (19).

Based on calculated pairwise $\mathrm{F}_{\mathrm{ST}}$ values and similar allele frequencies observed in the research field over time, little or no genetic drift occurred in this research population thus far. However, it is difficult to quantify drift because it is not certain how many generations have occurred since the founding of the research field population. In agreement with the calculated pairwise $\mathrm{F}_{\mathrm{ST}}$ values, neither dendrograms nor minimum spanning networks provided evidence of high differentiation among research field samples from different years, or progeny from the in vitro cross.

The plasticity of the genus Phytophthora has been noted previously $(29,34)$. This report of four novel alleles at two of the five loci studied (two alleles at each locus) suggests that high rates of mutation may contribute to this plasticity in $P$. capsici. It is likely that new alleles were not detected among the in vitro progeny, or in the first 2 years of the field study due to sample size, because novel alleles are relatively rare (based on their infrequent detection in the 2011 and 2012 field samples). We cannot be certain how many generations occur annually in this field; however, attempts to germinate oospores of Phytophthora spp. in the lab suggest that a maturation time of $\approx 1$ month is required, and germination of oospores formed during the in vitro cross in this study are consistent with this observation. Assuming a 4-month growing season when host tissue is in the field and temperatures are conducive to growth of $P$. capsici, a maximum of 17 generations might have occurred between September 2008 and the end of the 2012 growing season. If this assumption is correct, then the mutations observed in this population occurred at a rate of at least 0.047 mutations per locus per sexual generation, although this number could be inflated if mutations occurred during asexual reproduction (14). Although no new alleles were observed in the two parental isolates over $>5$ years of asexual propagation in the lab (data not shown), we cannot rule out the possibility that somatic mutations are occurring at these loci in the field. Mutation rates are generally expected to be higher at microsatellite loci than in other parts of the genome, and this mutation rate is in line with some of the higher microsatellite mutation rates observed in some animals (14) and in chickpea (Cicer arietinum) (49). Lamour et al. (34) compared nine $P$. capsici isolates using restriction-site-associated DNA sequencing, and found a high density of single-nucleotide variants among $P$. capsici isolates $(23.4 / \mathrm{kb})$. They also speculated that the relatively high proportion of $P$. capsici single-nucleotide variants in coding regions of the genome could be evidence for overall high mutation rates in $P$. capsici.

Because a small number of loci were used in this study, we cannot conclude that $P$. capsici has an inherently high mutation rate at all microsatellite loci or in all parts of the genome. Loci Pcap1 and Pcap7 could simply be highly mutable. A study of microsatellite mutations in humans found that mutations occurred at some loci but not others, and the authors observed more mutations at loci with a tetranucleotide repeat than at loci with a dinucleotide repeat (52). Udupa and Baum (49) also observed variation in mutation rates at chickpea loci and found a positive correlation between the number of repeats in the ancestral microsatellite allele at a locus and the number of mutations. The number of loci and mutations in the present study were too small to determine whether a similar pattern exists in P. capsici. Both Weber and Wong (52) and Udupa and Baum (49) reported that the most frequent mutation was gain or loss of a single copy of the repeat motif, with gain or loss of more than one copy of the repeat still occurring but at a much lower rate. These observations are consistent with the stepwise mutation model, as are the novel alleles observed at locus Pcap7 in this study. The 392-bp allele at this locus could have resulted from two sequential mutations, each adding a single repeat unit. However, mutations at the Pcap1 locus do not fit this model, suggesting that the stepwise mutation model may not fully describe the occurrence of mutations in $P$. capsici at the microsatellite loci described here.

The unusual patterns of inheritance observed in the F1 progeny from the in vitro cross are similar to what has been previously 
reported for $P$. cinnamomi (11), $P$. infestans (9), and $P$. parasitica (16). Mechanisms proposed in these studies include nondisjunction and the initial presence of heterokaryotic nuclei in oospores. Vercauteren et al. (50) also reported the inheritance of an allele from just one parent in crosses between isolates of $P$. ramorum, and speculated that it could be attributed to anomalous meiosis. Our observations are also similar to what Lamour et al. (34) described as "loss of heterozygosity," which was observed in 23 of 65 progeny from an in vitro cross between isolates of $P$. capsici. In some of these progeny, loss of heterozygosity was associated with a change in mating type or with loss of pathogenicity on cucumber and pepper fruit over 6 years of storage and culturing in the lab. The authors speculated that the cause could be deletion of one allele at a locus, translocation, homologous recombination, or gene conversion. Chamnanpunt et al. (10) also detected conversion to homozygosity in a linkage group that included the $A v r l b$ avirulence gene in $P$. sojae, with rates between $5 \times 10^{-4}$ and $3 \times 10^{-2}$ per locus per nucleus per generation. The authors attributed their observations to gene conversion without crossing over, resulting in heterokaryotic progeny. They observed this phenomenon in both F1 progeny, and also in single-zoospore lines vegetatively propagated in the lab, but saw higher rates of conversion to homozygosity following sexual reproduction. Conversion rates also differed between crosses and appeared to favor certain alleles over others. Abu-El Samen et al. (1) reported genetic variation in $P$. infestans among single-zoospore progeny from a single hyphal tip isolate, attributing it to some combination of spontaneous mutation, gene conversion, mitotic crossing over, or extrachromosomal elements. It should be noted that, in our study, the observation of an allele from only one parent at locus Pcap7 was interpreted as presence of two copies of that allele in the isolate. However, we cannot rule out the possibility of a null allele at this locus, because homozygosity cannot be distinguished from the presence of a null allele in our data set.

Previous reports of loss of heterozygosity in P. capsici have been in progeny from crosses made in the lab. The observation of numerous isolates collected from the field in 2009 with the same allele patterns observed in the in vitro progeny could be the first evidence that loss of heterozygosity also occurs in the field. The number of generations occurring between the inoculation of the field on 8 September 2008 and 22 June 2009 (when the first isolates were collected from the field) cannot be determined with certainty. However, the fact that this unusual recombination was observed early in the 2009 growing season is consistent with the hypothesis that some of these field isolates are, in fact, F1 progeny. Because alleles at these five loci were invariable in the parent isolates over numerous transfers in the lab, we did not investigate the possibility that genetic variation observed in the progeny could be occurring during asexual as well as sexual reproduction, as Abu-El Samen et al. (1) and Chamnanpunt et al. (10) reported in $P$. infestans and $P$. sojae, respectively.

Previous work has demonstrated that, once $P$. capsici is introduced into a field, gene flow between fields is limited $(13,33)$. Furthermore, depending on when and how $P$. capsici was introduced into a grower's field, the gene pool of the founding population could be quite small. However, in commercial fields, it is not always known exactly when the pathogen was first introduced. It would be virtually impossible to be certain of the identity of the founding individuals or to know that no subsequent introductions had occurred. For these reasons, the research field described here presents a unique opportunity to study the population genetics of $P$. capsici and to investigate how such high levels of diversity are maintained in fields where gene flow is limited. In this study, high levels of diversity were maintained over time, and little evidence of genetic drift and four new alleles were observed, using only five microsatellite loci and mating types to characterize isolates. It is likely that other genotyping methods would provide additional information about this isolated population. The fact that $P$. capsici is heterothallic and, therefore, that sexual recombination is required to form overwintering structures, as well as the lack of aerial dispersal, have long been assumed to affect the genetic structure of field populations. The results of this study suggest that spontaneous mutation as well as mechanisms such as loss of heterozygosity or abnormal meiosis also play important roles.

\section{ACKNOWLEDGMENTS}

This project was supported by the Agriculture and Food Research Initiative Competitive Grant Number 2012-67011-19690 from the United States Department of Agriculture National Institute of Food and Agriculture and by the New York State Department of Agriculture and Markets through an NY Specialty Crops Block Grant. Support for A. R. Dunn was also provided by a fellowship from Cornell University College of Agriculture and Life Sciences, and by an award from the Storkan-HanesMcCaslin Foundation. We thank H. W. Lange, S. Reiners, B. Nesin, M. Day, E. Wyckoff, and E. Call for technical assistance.

\section{LITERATURE CITED}

1. Abu-El Samen, F. M., Secor, G. A., and Gudmestad, N. C. 2003. Genetic variation among asexual progeny of Phytophthora infestans detected with RAPD and AFLP markers. Plant Pathol. 52:314-325.

2. Agapow, P. M., and Burt, A. 2001. Indices of multilocus linkage disequilibrium. Mol. Ecol. Notes 1:101-102.

3. Babadoost, M., and Pavon, C. 2013. Survival of oospores of Phytophthora capsici in soil. Plant Dis. 97:1478-1483.

4. Bi, Y., Cui, X., Lu, X., Cai, M., Liu, X., and Hao, J. J. 2011. Baseline sensitivity of natural population and resistance of mutants in Phytophthora capsici to zoxamide. Phytopathology 101:1104-1111.

5. Bowers, J. H., Papavizas, G. C., and Johnston, S. A. 1990. Effect of soil temperature and soil-water matric potential on the survival of Phytophthora capsici in natural soil. Plant Dis. 74:771-777.

6. Brown, A., Feldman, M. W., and Nevo, E. 1980. Multilocus structure of natural populations of Hordeum spontaneum. Genetics 96:523-536.

7. Bruvo, R. R., Michiels, N. K. N., D'Souza, T. G. T., and Schulenburg, H. H. 2004. A simple method for the calculation of microsatellite genotype distances irrespective of ploidy level. Mol. Ecol. 13:2101-2106.

8. Camp, A. R., Dillard, H. R., and Smart, C. D. 2008. Efficacy of Muscodor albus for the control of Phytophthora blight of sweet pepper and butternut squash. Plant Dis. 92:1488-1492.

9. Carter, D. A., Buck, K. W., Archer, S. A., Van der Lee, T., Shattock, R. C., and Shaw, D. S. 1999. The detection of nonhybrid, trisomic, and triploid offspring in sexual progeny of a mating of Phytophthora infestans. Fungal Genet. Biol. 26:198-208.

10. Chamnanpunt, J., Shan, W., and Tyler, B. 2001. High frequency mitotic gene conversion in genetic hybrids of the oomycete Phytophthora sojae. Proc. Natl. Acad. Sci. USA 98:14530-14535.

11. Dobrowolski, M. P., Tommerup, I. C., Blakeman, H. D., and O'Brien, P. A. 2002. Non-Mendelian inheritance revealed in a genetic analysis of sexual progeny of Phytophthora cinnamomi with microsatellite markers. Fungal Genet. Biol. 35:197-212.

12. Donahoo, R. S., and Lamour, K. H. 2008. Interspecific hybridization and apomixis between Phytophthora capsici and Phytophthora tropicalis. Mycologia 100:911-920

13. Dunn, A. R., Milgroom, M. G., Meitz, J. C., McLeod, A., Fry, W. E., McGrath, M. T., Dillard, H. R., and Smart, C. D. 2010. Population structure and resistance to mefenoxam of Phytophthora capsici in New York State. Plant Dis. 94:1461-1468.

14. Ellegren, H. H. 2000. Microsatellite mutations in the germline: Implications for evolutionary inference. Trends Genet. 16:551-558.

15. Excoffier, L. L., and Lischer, H. E. L. H. 2010. Arlequin suite ver. 3.5: A new series of programs to perform population genetics analyses under Linux and Windows. Mol. Ecol. Resour. 10:564-567.

16. Forster, H., and Coffey, M. 1990. Mating behavior of Phytophthora parasitica: Evidence for sexual recombination in oospores using DNA restriction fragment length polymorphisms as genetic markers. Exp. Mycol. 14:351-359.

17. Gevens, A. J., Donahoo, R. S., Lamour, K. H., and Hausbeck, M. K. 2007. Characterization of Phytophthora capsici from Michigan surface irrigation water. Phytopathology 97:421-428.

18. Gobena, D., Roig, J., Galmarini, C., Hulvey, J., and Lamour, K. 2012. Genetic diversity of Phytophthora capsici isolates from pepper and pumpkin in Argentina. Mycologia 104:102-107.

19. Goodwin, S. B. 1997. The population genetics of Phytophthora. 
Phytopathology 87:462-473.

20. Granke, L. L., Quesada-Ocampo, L. M., Lamour, K., and Hausbeck, M. 2012. Advances in research on Phytophthora capsici on vegetable crops in the United States. Plant Dis. 95:1588-1600.

21. Grünwald, N. J., Goodwin, S. B., Milgroom, M. G., and Fry, W. E. 2003. Analysis of genotypic diversity data for populations of microorganisms. Phytopathology 93:738-746.

22. Grünwald, N. J., and Hoheisel, G.-A. 2006. Hierarchical analysis of diversity, selfing, and genetic differentiation in populations of the Oomycete Aphanomyces euteiches. Phytopathology 96:1134-1141.

23. Hu, J., Pang, Z., Bi, Y., Shao, J., Diao, Y., Guo, J., Liu, Y., Lu, H., Lamour, K., and Liu, X. L. 2013. Genetically diverse long-lived clonal lineages of Phytophthora capsici from pepper in Gansu, China. Phytopathology 103:920-926.

24. Hurlbert, S. H. 1971. The nonconcept of species diversity: A critique and alternative parameters. Ecology 52:577-586.

25. Hurtado-Gonzáles, O., Aragon-Caballero, L., Apaza-Tapia, W., Donahoo, R., and Lamour, K. 2008. Survival and spread of Phytophthora capsici in coastal Peru. Phytopathology 98:688-694.

26. Hurtado-Gonzáles, O. P., and Lamour, K. H. 2009. Evidence for inbreeding and apomixis in close crosses of Phytophthora capsici. Plant Pathol. 58:715-722.

27. Jones, L. A., Worobo, R. W., and Smart, C. D. 2012. Oomycete and bacterial pathogens in New York surface irrigation water: Survey results and ultraviolet treatment. (Abstr.) Phytopathology 102:S4.60.

28. Judelson, H. S. 1997. Expression and inheritance of sexual preference and selfing potential in Phytophthora infestans. Fungal Genet. Biol. 21:188197.

29. Judelson, H. S. 2007. Genomics of the plant pathogenic oomycete Phytophthora: Insights into biology and evolution. Pages 97-141 in: Fungal Genomics. J. C. Dunlap, ed. Advances in Genetics, Elsevier, San Diego, CA

30. Kamvar, Z. N., Tabima, J. F., and Grünwald, N. J. 2013. poppr: An R package for genetic analysis of populations with mixed (clonal/sexual) reproduction. http://cran.r-project.org/package=poppr

31. Keb-Llanes, M., González, G., Chi-Manzanero, B., and Infante, D. 2002. A rapid and simple method for small-scale DNA extraction in Agavaceae and other tropical plants. Plant Mol. Biol. Rep. 20:299.

32. Lamour, K. H., and Hausbeck, M. K. 2000. Mefenoxam insensitivity and the sexual stage of Phytophthora capsici in Michigan cucurbit fields. Phytopathology 90:396-400.

33. Lamour, K. H., and Hausbeck, M. K. 2001. Investigating the spatiotemporal genetic structure of Phytophthora capsici in Michigan. Phytopathology 91:973-980.

34. Lamour, K. H., Mudge, J., Gobena, D., Hurtado-Gonzales, O. P., Schmutz, J., Kuo, A., Miller, N. A., Rice, B. J., Raffaele, S., Cano, L. M., Bharti, A. K., Donahoo, R. S., Finley, S., Huitema, E., Hulvey, J., Platt, D., Salamov, A., Savidor, A., Sharma, R., Stam, R., Storey, D., Thines, M., Win, J., Hass, B. J., Dinwiddie, D. L., Jenkins, J., Knight, J. R., Affourtit, J. P., Han, C. S., Chertkov, O., Lindquist, E. A., Detter, C., Grigoriev, I. V., Kamoun, S., and Kingsmore, S. F. 2012. Genome sequencing and mapping reveal loss of heterozygosity as a mechanism for rapid adaptation in the vegetable pathogen Phytophthora capsici. Mol. Plant-Microbe Interact. 25:1350-1360.

35. Liu, B., Roos, D., Buttler, S., Richter, B., and Louws, F. J. 2012.
Vegetable seedling diseases associated with earthworm castings contaminated with Phytophthora capsici and Pythium attrantheridium. Plant Health Progress. doi:10.1094/PHP-2012-0421-01-RS

36. Lu, X., Hausbeck, M., Liu, X., and Hao, J. J. 2011. Wild type sensitivity and mutation analysis for resistance risk to fluopicolide in Phytophthora capsici. Plant Dis. 95:1535-1541.

37. Meitz, J. C., Linde, C. C., Thompson, A., Langenhoven, S., and McLeod, A. 2010. Phytophthora capsici on vegetable hosts in South Africa: Distribution, host range and genetic diversity. Australas. Plant Pathol. 39:431-439.

38. Pavon, C. F., Babadoost, M., and Lambert, K. N. 2008. Quantification of Phytophthora capsici oospores in soil by sieving-centrifugation and realtime polymerase chain reaction. Plant Dis. 92:143-149.

39. Peakall, R., and Smouse, P. E. 2006. GENALEX 6: Genetic analysis in Excel. Population genetic software for teaching and research. Mol. Ecol. Notes 6:288-295.

40. Peakall, R., and Smouse, P. E. 2012. GenAlEx 6.5: Genetic analysis in Excel. Population genetic software for teaching and research—an update. Bioinformatics 28:2537-2539.

41. R Development Core Team. 2013. R: A Language and Environment for Statistical Computing. http://www.R-project.org/

42. Roberts, P. D., Urs, R. R., French-Monar, R. D., Hoffine, M. S., Seijo, T. E., and McGovern, R. J. 2005. Survival and recovery of Phytophthora capsici and oomycetes in tailwater and soil from vegetable fields in Florida. Ann. Appl. Biol. 146:351.

43. Satour, M. M., and Butler, E. E. 1968. Comparative morphological and physiological studies of the progenies from intraspecic matings of Phytophthora capsici. Phytopathology 58:183-192.

44. Schmitthenner, A. F., and Bhat, R. G. 1994. Useful Methods for Studying Phytophthora in the Laboratory. Department of Plant Pathology, Ohio Agricultural Research and Development Center, The Ohio State University, Wooster.

45. Shattock, R. C., Tooley, P. W., and Fry, W. E. 1986. Genetics of Phytophthora infestans: Characterization of single-oospore cultures from A1 isolates induced to self by intraspecific stimulation. Phytopathology 76:407-410.

46. Sheskin, D. J. 1996. Handbook of Parametric and Nonparametric Statistical Procedures. CRC Press, Boca Raton, FL.

47. Stoddart, J. A., and Taylor, J. F. 1988. Genotypic diversity: Estimation and prediction in samples. Genetics 118:705-711.

48. Uchida, J. Y., and Aragaki, M. 1980. Chemical stimulation of oospore formation in Phytophthora capsici. Mycologia 72:1103-1108.

49. Udupa, S. M., and Baum, M. 2001. High mutation rate and mutational bias at (TAA) $)_{\mathrm{n}}$ microsatellite loci in chickpea (Cicer arietinum $\mathrm{L}$.). Mol. Genet. Genomics 265:1097-1103

50. Vercauteren, A., Boutet, X., D'hondt, L., Van Bockstaele, E., Maes, M., Leus, L., Chandelier, A., and Heungens, K. 2011. Aberrant genome size and instability of Phytophthora ramorum oospore progenies. Fungal Genet. Biol. 48:537-543.

51. Wang, Z. Y., Langston, D. B., Csinos, A. S., Gitaitis, R. D., Walcott, R. R., and Ji, P. S. 2009. Development of an improved isolation approach and simple sequence repeat markers to characterize Phytophthora capsici populations in irrigation ponds in southern Georgia. Appl. Environ. Microbiol. 75:5467-5473.

52. Weber, J. L., and Wong, C. 1993. Mutation of human short tandem repeats. Hum. Mol. Genet. 2:1123-1128. 